\title{
Changes in Body Mass Index across Age Groups in Iranian Women: Results from the National Health Survey
}

\author{
Enayatollah Bakhshi, ${ }^{1}$ Behjat Seifi, ${ }^{2}$ Akbar Biglarian, ${ }^{1}$ and Kazem Mohammad ${ }^{3}$
}

${ }^{1}$ Department of Statistics and Computer, University of Social Welfare and Rehabilitation Sciences, Tehran, Iran

${ }^{2}$ Department of Physiology, Medicine School, Tehran University of Medical Sciences, Tehran, Iran

${ }^{3}$ Department of Biostatistics, School of Public Health and Institute of Public Health Research,

Tehran University of Medical Sciences, Tehran, Iran

Correspondence should be addressed to Enayatollah Bakhshi, bakhshi@razi.tums.ac.ir

Received 19 July 2011; Revised 12 October 2011; Accepted 16 October 2011

Academic Editor: Abdulrahman O. Musaiger

Copyright (๑) 2012 Enayatollah Bakhshi et al. This is an open access article distributed under the Creative Commons Attribution License, which permits unrestricted use, distribution, and reproduction in any medium, provided the original work is properly cited.

\begin{abstract}
Background. To investigate the associations between some factors with weight gain across age groups in Iranian women. Methods. Proportional odds model was used to estimate the probability of BMI categorized as a function of education, economic index, workforce, smoking, marital status, and place of residence adjusted for age, using data from the "National Health Survey in Iran" database. It included 14176 women aged 20-69 years. Results. For all covariates, age was directly associated with overweight and obesity before 60 years of age. Among women aged 20-40 years, the rates of change in probabilities of overweight and obesity were highest. Among women, being inactive, with high economic index, married, being nonsmoker, in an urban residence, with lower educational attainment, all increased the probabilities of overweight and obesity. Conclusions. Women aged 20-40 years gained weight faster than other groups. They may need additional information and more support on how to reduce their risk for weight gain through positive health behaviors.
\end{abstract}

\section{Introduction}

Overweight and obesity are as public health problems, due to both their rapid growth in recent decades and to their related health disorders, such as cardiovascular diseases, diabetes, some cancers, and other diseases [1-8]. Studies have also showed relationships between obesity and chronic pain [9] and Alzheimer's disease [10].

In 2002, nearly half a billion of the world population considered to be overweight or obese [11]. Obesity is assuming epidemic proportions in both developed and developing countries [12-15]. In 2003-04, 17.1\% of US children and adolescents were overweight and $32.2 \%$ of adults were obese [16]. Almost one third of adult Canadians are at increased risk of disability, disease, and premature death due to obesity [17]. Obesity is relatively common in Europe, especially in southern and eastern countries, and studies from repeated surveys suggest that the prevalence of obesity has been increasing last years [18]. Up to 2000, the prevalence of obesity in Western countries was suggested to vary between 15 percent and 20 percent [19].

In recent years, the statistics were appalling. The prevalence of obesity in USA, Canada, Australia, United Kingdom, Iran, and Egypt was 31.8, 24.3, 25.1, 24.9, 21.6, and 34.6, respectively [20]. Overall, more than one out of ten of the world adult population was obese. Nearly 1.5 billion adults, 20 and older, are now considered to be overweight or obese. Of these, nearly 300 million women and more than 200 million men were obese [21]. In 2010, almost 43 million children (35 million in developing countries and 8 million in developed countries) were estimated to be overweight or obese [22].

Most studies have investigated the relationship between sociodemographic factors and obesity. It has found a significant association between weight gain and aging [23-26].

Sobal and Stunkard [27] found a strong inverse relationship between socioeconomic status and obesity in women in affluent societies, with a higher proportion of obese women 
in lower socioeconomic groups. In low-income countries, obesity is more common among middle-age women, people of higher socioeconomic status, and people living in urban communities $[28,29]$.

Although the association of overweight with smoking, alcohol consumption, dietary habits, and physical activity has been analyzed in many studies, the findings are not consistent. Wilsgaard et al. [30] showed that being a smoker is associated with lower BMI values.

We aimed to assess the associations between some factors with weight gain across age groups among women by using cross-sectional data from the National Health Survey in Iran (NHSI).

\section{Material and Methods}

2.1. Study Population. The National Health Survey in Iran (NHSI) is a survey designed to gain comprehensive knowledge and information about health care problems and difficulties throughout the country, 1999-2000. The survey was conducted under the supervision and with the financial support of the Iranian Ministry of Health and Medical Education. The population sample of the survey consisted of one thousandth of the total Iranian population; nonIranian were excluded. They were randomly chosen by cluster sampling. Each cluster comprises of 8 households. The choice of 8 households for the cluster size was based on one-day performance capacity of the data collection group: four persons (2 physicians, 1 interviewer, and 1 lab technician). The statistical framework was based on the household lists available with every Health Department in the provinces, usually updated annually. Data from the National Health Survey were considered in this investigation. In this study, 14176 women, 8957 urban, and 5219 rural aged 20-69 years were investigated. These data were collected by the National Research Center of Medical Sciences and are presented partially at the Department of Biostatistics and Epidemiology/Tehran University of Medical Sciences for research [31]. We excluded pregnant women from the analyses. This study was approved by the Ethic Committee of the University of Social Welfare and Rehabilitation Sciences.

\subsection{Measurements}

2.2.1. Response Variable. Height and weight were measured rather than self-reported. Height was measured without shoes to the nearest $5 \mathrm{~mm}$. Weight was measured to the nearest $0.1 \mathrm{~kg}$ with the subject in light indoor clothes, with emptied pockets and without shoes. BMI (body mass index) was calculated as weight in kilograms divided by square of height in meters, squared, and subjects were classified into underweight defined as BMI $<18.5$, normal weight as BMI 18.524.9, overweight as BMI 25.0-29.9, and obese as BMI $\geq 30$.

\subsubsection{Independent Variables}

Age. Information about the respondent age was based on their self-reported birth year, and subjects were stratified into five 10-year age groups $(20-29,30-39,40-49,50-59$, and $60-$ 69 years).
Education. Educational level was measured in years of school. Years of schooling were divided into three groups: person with basic ( $0-8$ years), moderate ( $9-12$ years), or high (more than 12 years) education.

Economic Index. Due to ethical considerations, we did not ask respondents about their income. Because they were afraid of paying their taxes. We surrogated economic index for their household income. Economic index was defined as square meter of living place divided by number of household. Participants were classified by their economy index status into four classes: (1) low (economic index $\leq$ Quartile 1), (2) lower-middle (Quartile $1<$ economic index $\leq$ Quartile 2), (3) upper-middle (Quartile $2<$ economic index $\leq$ Quartile 3 ), and (4) high (economic index $>$ Quartile 3).

Place of Residence. The subjects were grouped according to their place of residence as living in cities (urban) or villages (rural).

Workforce. Active workforce was defined as the part of the female population that belongs to the currently employed (as employees) or self-employed category as opposed to inactive workforce (being a housewife/houseworker, pensioner, student, or unemployed).

Smoking. Smoking status was dichotomized into smoker (those who smoke every day and have smoked at least 100 cigarettes in their lives) versus nonsmoker (others).

Marital Status. To make the marital status variable, it was dichotomized into legally married and nonmarried groups.

Note that we have no information on household income and physical activity, but economic index is surrogate for household income and we used workforce factor. Due to ethical considerations, we did not ask respondents about their income, because they were afraid of paying their taxes. The consumption of alcohol is prohibited in Iran. Therefore, there were no information on alcohol consumption.

2.3. Statistical Analysis. We used proportional odds model to assess the influence of the independent variables listed previously on the probability of obesity and overweight. We carried out score tests for the proportional odds assumption, which was found to hold. In addition, we tested the interaction terms using reduced models excluding nonsignificant terms. For obesity and overweight, odds ratios and 95\% confidence intervals were calculated. For all covariates, we calculated the probability of obesity and overweight across age groups. All analyses were performed using SAS software, version 9.1 for windows.

\section{Results}

The mean BMI of women was $25.33 \mathrm{~kg} \mathrm{~m}^{-2}$ (95\% CI: $25.25-$ 25.41). Prevalence (\%) of the body mass index levels according to independent variables was assessed (Table 1). Table 1 shows that obesity is much more prevalent among women 
TABLE 1: Prevalence (\%) of underweight, normal weight, overweight, and obesity according to sociodemographic and smoking in a random sample of 14176 women in Iran, 1999-2000.

\begin{tabular}{|c|c|c|c|c|}
\hline Variable & Underweight & Normal weight & overweight & obese \\
\hline \multicolumn{5}{|l|}{ Age group (years) } \\
\hline $20-30$ & 10.5 & 57.8 & 22.6 & 9.1 \\
\hline $30-40$ & 4.0 & 42.4 & 33.5 & 20.1 \\
\hline $40-50$ & 3.2 & 35.8 & 35.2 & 25.8 \\
\hline $50-60$ & 2.6 & 35.0 & 37.1 & 25.3 \\
\hline $60-69$ & 4.4 & 41.4 & 36.2 & 18.0 \\
\hline \multicolumn{5}{|l|}{ Education level } \\
\hline Basic & 5.8 & 44.6 & 30.8 & 18.8 \\
\hline Moderate & 6.5 & 47.9 & 30.9 & 14.6 \\
\hline High & 11.0 & 63.4 & 19.9 & 5.7 \\
\hline \multicolumn{5}{|l|}{ Economic index } \\
\hline Low & 8.0 & 50.6 & 27.2 & 14.2 \\
\hline Lower-middle & 5.5 & 44.2 & 30.9 & 19.4 \\
\hline Upper-middle & 5.4 & 45.0 & 31.5 & 18.1 \\
\hline High & 5.2 & 42.9 & 32.9 & 19.0 \\
\hline \multicolumn{5}{|l|}{ Workforce } \\
\hline Inactive & 5.2 & 44.0 & 31.8 & 18.9 \\
\hline Active & 13.1 & 61.0 & 20.0 & 6.0 \\
\hline \multicolumn{5}{|l|}{ Smoking status } \\
\hline Nonsmoker & 6.1 & 45.9 & 30.5 & 17.5 \\
\hline Smoker & 6.6 & 46.5 & 31.1 & 15.8 \\
\hline \multicolumn{5}{|l|}{ Marital status } \\
\hline Non-married & 8.1 & 49.4 & 29.9 & 12.6 \\
\hline Married & 5.6 & 45.0 & 30.6 & 18.8 \\
\hline \multicolumn{5}{|l|}{ Place of residence } \\
\hline Rural & 8.3 & 54.4 & 25.8 & 11.5 \\
\hline Urban & 4.8 & 41.0 & 33.2 & 21.0 \\
\hline
\end{tabular}

aged 40-60 years, less educated, high economic index, inactive workforce, nonsmoker, married, and resident in city.

We started by fitting a preliminary proportional odds model including only age to observe the influence of the potential confounders on overweight and obesity. Unadjusted odds ratios were $2.50,3.41,3.52$, and 2.45 for age groups $30-40,40-50,50-60$, and 60-69 years, respectively.

To assess effects of factors in obesity and overweight across age groups, adjustment for age was performed by using proportional odds model. With four response categories, the model had three intercepts. They are of interest for computing response probabilities. For all covariates, the probability of overweight and obesity was calculated. The results are presented in Figures 1-6.

Figures 1-6 show that age was directly associated with overweight and obesity before 60 years of age. In other words, the probabilities of overweight and obesity increase from 20 to about 50 years of age and decrease after age 60 years. The curves are either flat or in increase in the 50-60 age group. We observe rise in a very high rate among women aged 20 40 years.
We used proportional odds model including age, economic index, workforce status, education level, place of residence, smoking status, and marital status. All were significantly associated with underweight, normal weight, overweight, and obesity. Odds ratios and 95\% confidence intervals were calculated (Table 2).

Table 2 shows that among women, being inactive, with high economic index, married, being nonsmoker, in an urban residence, with lower educational attainment, all increased the probability of overweight and obesity. Younger age decreased the probability of overweight and obesity. The odds ratios were 2.16 (95\% CI: 1.96-2.35), 2.93 (95\% CI: 2.67-3.23), 2.96 (95\% CI: 2.63-3.32), and 1.99 (95\% CI: $1.76-2.25)$ for age groups $30-40,40-50,50-60$, and 60-69 years, respectively.

For overweight and obese participants with moderate and high education, odds ratios were 0.90 (95\% CI: 0.830.98 ) and 0.57 (95\% CI: 0.47-0.69), respectively.

Women with high economic index were more likely to be overweight and obese. The odds ratios for overweight and obese participants with lower-middle, upper-middle, and 


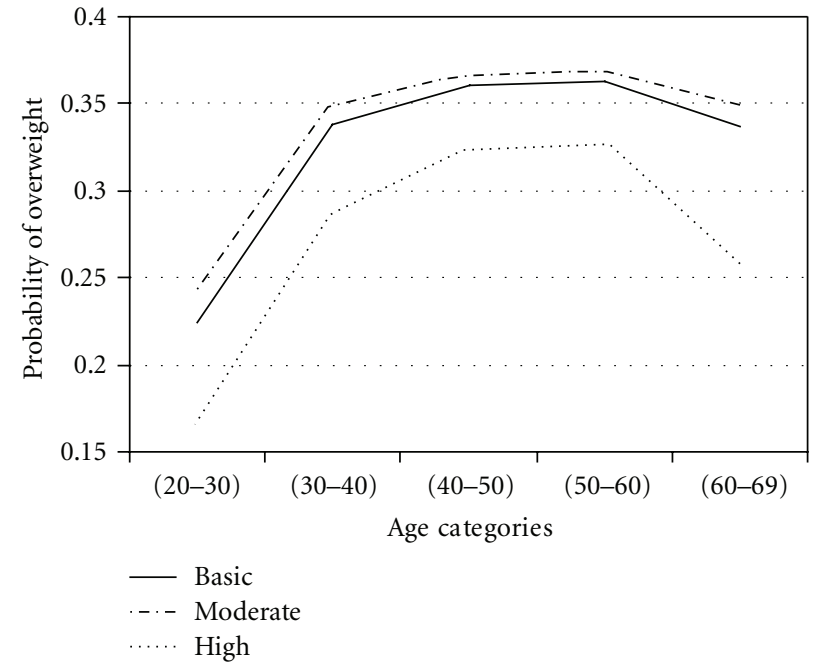

(a)

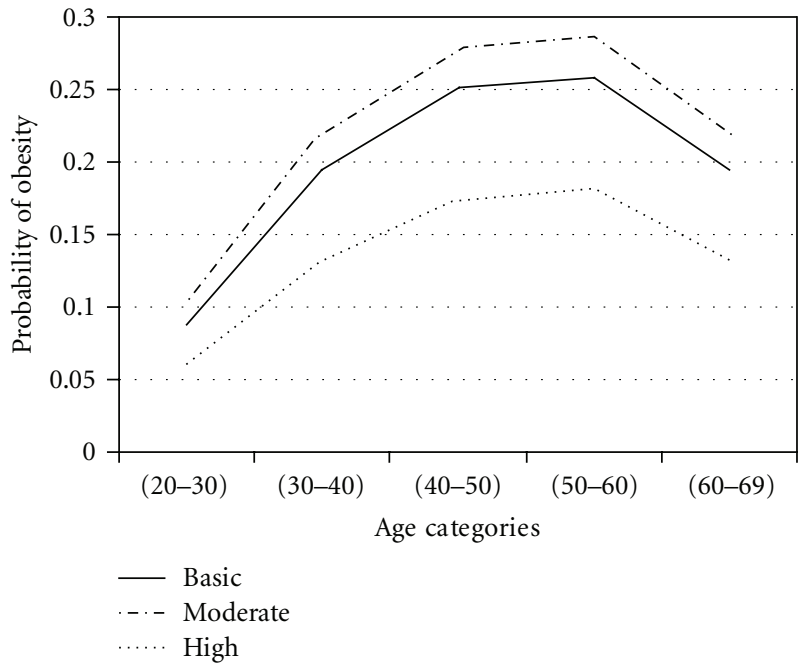

(b)

FIGURE 1: Probabilities of overweight and obesity across age groups for education level.

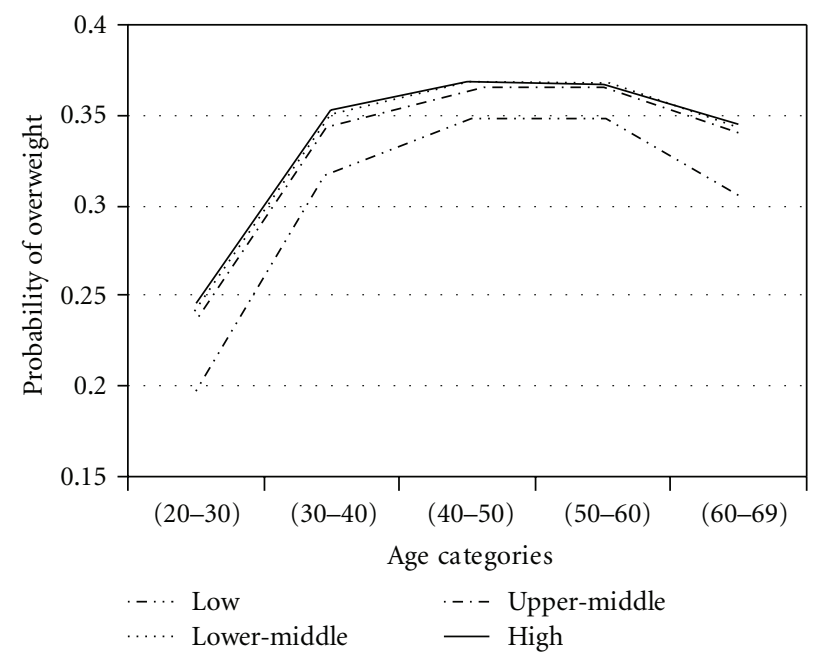

(a)

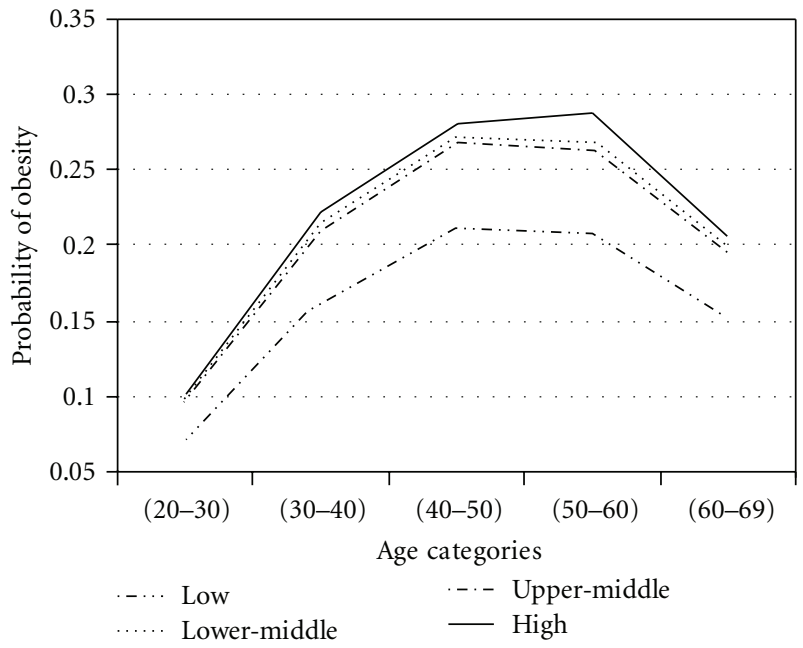

(b)

Figure 2: Probabilities of overweight and obesity across age groups for economic index.

high levels were 1.37 (95\% CI: 1.26-1.50), 1.38 (95\% CI: $1.27-1.51$ ), and 1.49 (95\% CI: 1.36-1.63), respectively.

We observed an association between workforce level and BMI groups. For active participants odds ratio was 0.57 (95\% CI: 051-0.64).

Overall, nonsmokers were more obese. For smokers, odds ratio was 0.68 (95\% CI: $0.54-0.85)$.

Among women, the odds for urban was 1.97 times that for rural (95\% CI: 1.84-2.11).

Married women were more obese. Odds ratio was 1.19 (95\% CI: 1.10-1.29).

\section{Discussion}

Concern about the increased prevalence of overweight and obesity has heightened interest in the association between some factors with weight gain across age groups. In this cross-sectional study we found probabilities of overweight and obesity by identifying a variety of factors that are associated with weight gain. Overall, probability of overweight is higher than probability of obesity. Age was directly associated with overweight and obesity before 60 years of age. The probabilities of overweight and obesity initially increased, and these probabilities decreased for women aged more than 60 years. It is possible that weight loss among older women is result of medical advice to control or prevent obesity-related chronic diseases. For all covariates, the highest probabilities of overweight and obesity were among women aged 5060 years. Among women aged 20-40 years, the rates of change in probabilities of overweight and obesity were highest. The mechanism of weight gain in women aged 20-40 years is likely multifactorial; that is, younger people 


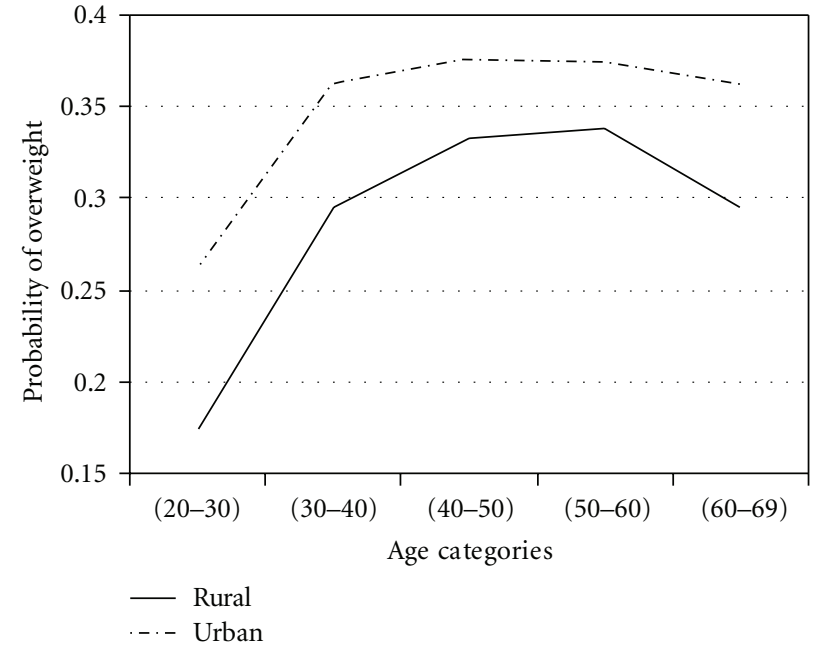

(a)

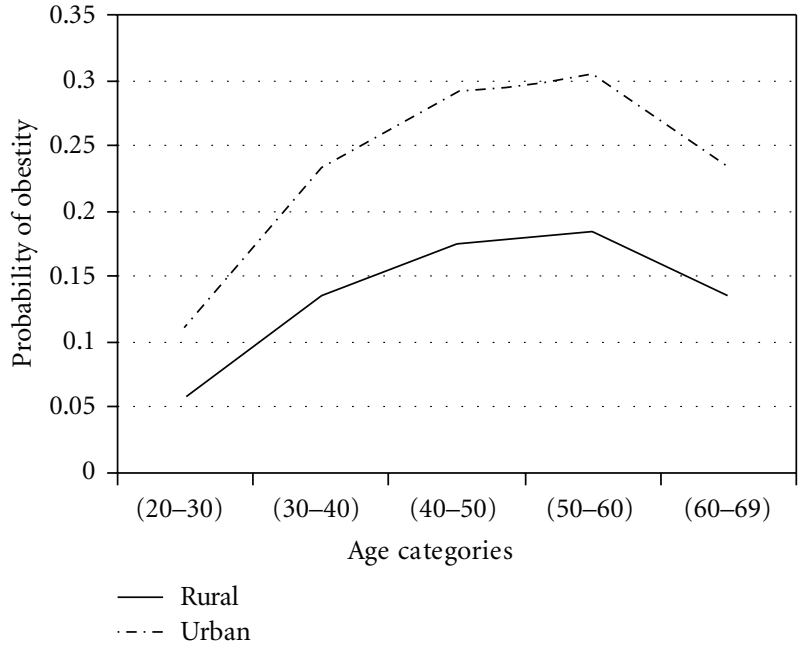

(b)

FIGURE 3: Probabilities of overweight and obesity across age groups for place of residence.

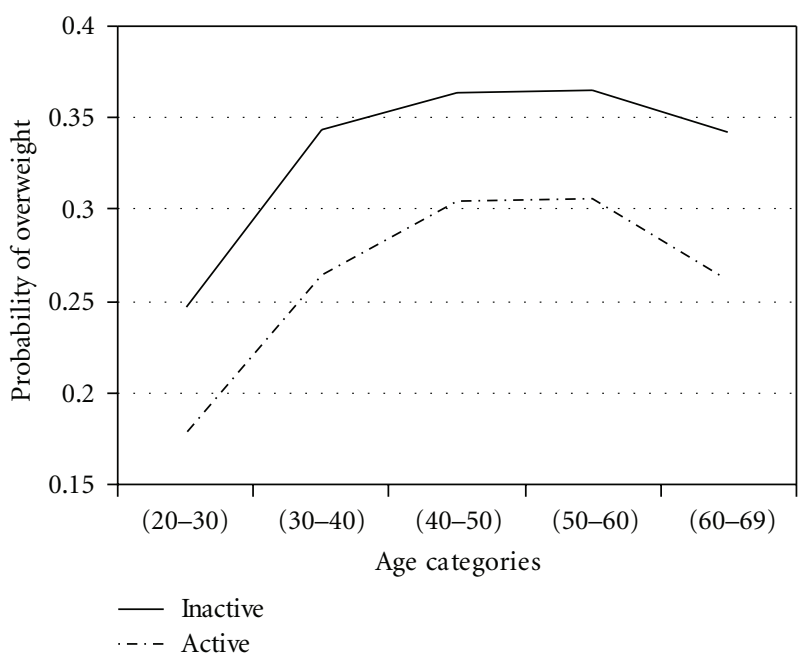

(a)

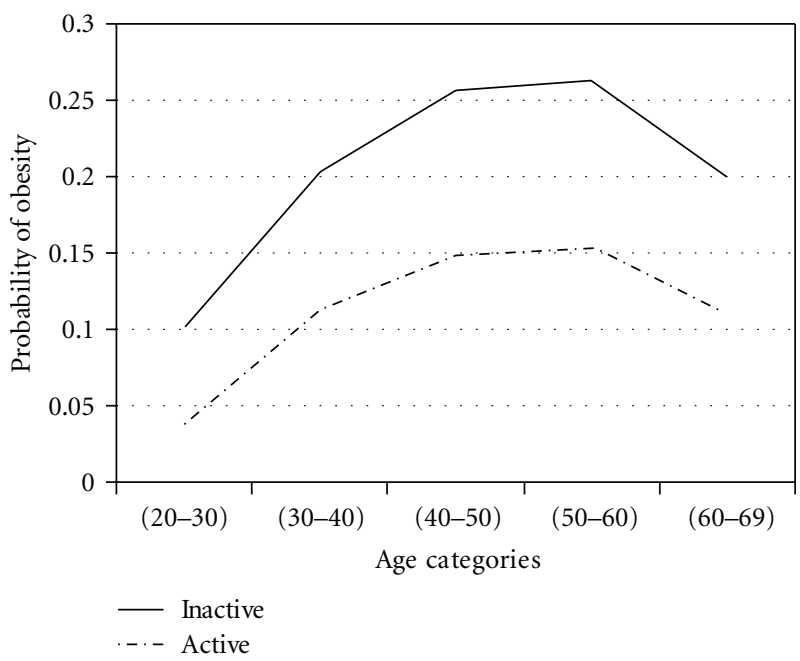

(b)

FIGURE 4: Probabilities of overweight and obesity across age groups for workforce level.

love fast food and their spouses have to follow them. An increased consumption of fast foods by young adults has been repeatedly shown to be associated with obesity and excess weight gain [32]. Although some studies showed that any association between number of children and weight gain is a result of lifestyle and behaviors associated with family life rather than being as result of the biological impact of pregnancy in women $[31,33]$, it may include physiological mechanisms in the women, especially after their pregnancy. Prevention of weight gain among women aged 20-40 years may have a significant public health impact [34] and further work is needed to understand these relationships.

Education. Women with moderate education had higher probabilities of overweight and obesity than high educated women. Our results are consistent with some studies
$[26,35-38]$. Note that the women with moderate education had higher probabilities of overweight and obesity than basic educated women. The differences in probabilities of overweight and obesity between high educated and two other levels were noticeable. Higher education may provide knowledge or resource influences on weight loss.

Economic Index. Many studies have found an inverse relation between socioeconomic level and weight [39-45]. It is not straightforward matter to compare those results with ours, because of the different study designs, time span, different region, and method of analysis. In our study, subjects with high level had higher probabilities of overweight and obesity than the other level. These results are consistent with the findings of some study in developing country [46]. In Iran, economy, business, social affair, and so forth are controlled 


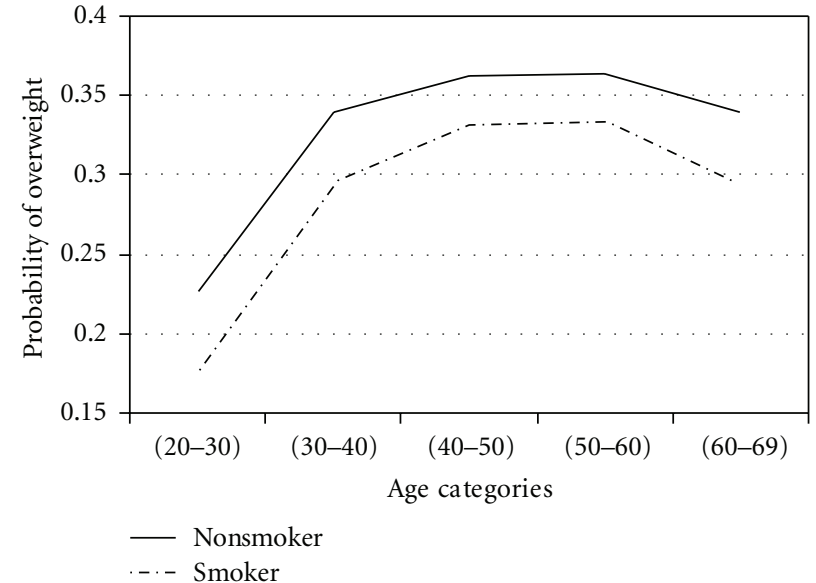

(a)

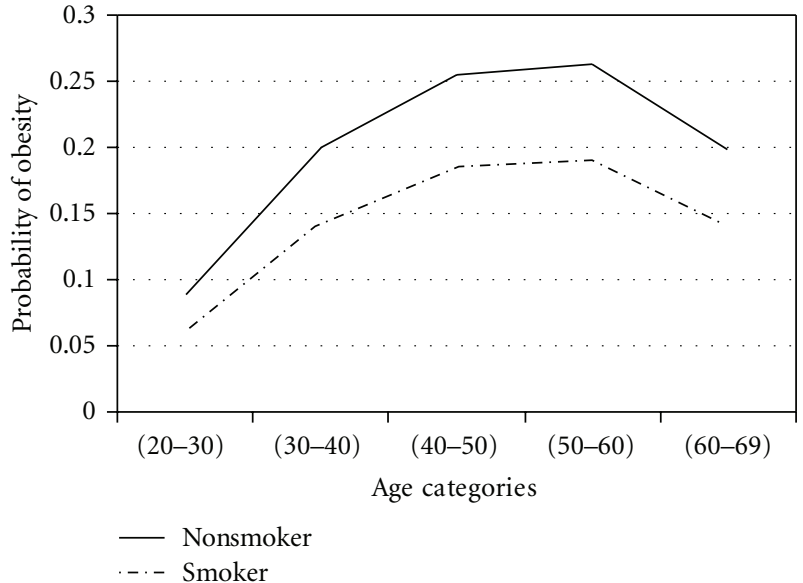

(b)

Figure 5: Probabilities of overweight and obesity across age groups for smoking status.

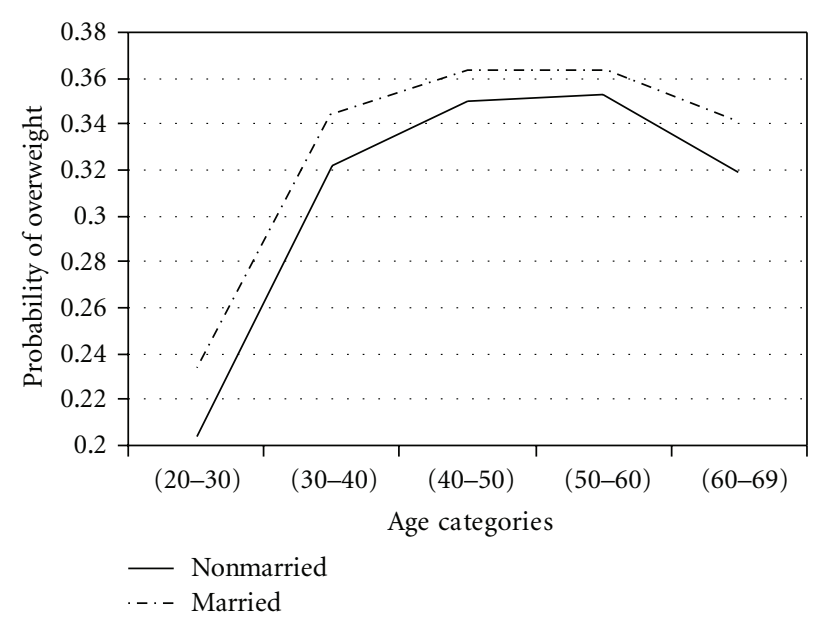

(a)

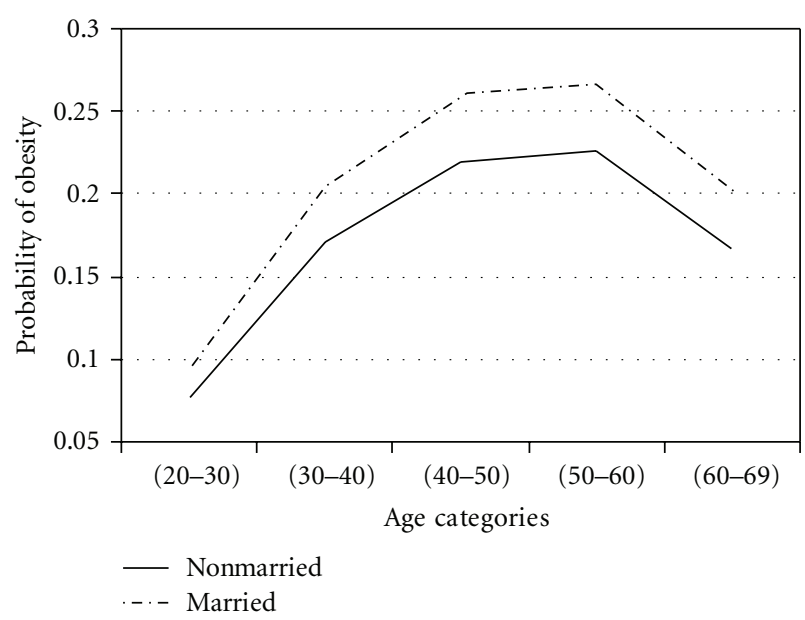

(b)

Figure 6: Probabilities of overweight and obesity across age groups for marital status.

by some people named Bazarry. These people have usually low education. Higher economy may not provide knowledge or resource influences on weight loss.

Residence. Urban women had higher probabilities of overweight and obesity than rural women. Among urban women, the probability of overweight initially increased and then changes were fairly slow but this decreasing was sharply in rural women aged $>60$ years. Among women aged 50-60 years, the probability of obesity for urban was approximately 2 times that for rural.

Workforce. Inactive women had higher probabilities of overweight and obesity than active women. Our results are consistent with some studies. For example, Swedish women who returned to work soon after pregnancy also retained less weight than women who stayed at home $[47,48]$. Obesity may be more acceptable among unemployed persons. It is also possible that there is more discrimination against the obese, or obese women may end up in lower status jobs through stronger selective processes in Iran. Another explanation for the effect of the workforce may involve energy expenditure at work or the structured lifestyle that active woman imposes.

Smoking. The increase in body weight by age was found to be lower among smokers than among nonsmokers. Biological mechanisms as well as psychological factors may be involved. An increase of energy expenditure while smoking, both in resting and in light physical activity conditions, may relate to weight loss in smokers. Our results are consistent with the findings of most studies [49-53].

Marital Status. Most studies showed that marriage is associated with weight gain $[54,55]$. The finding in this study showed that women who were married tended to gain more weight across the age than those who were not married. The rate of change in probability of overweight in aged $<40$ years 
TABLE 2: Adjusted* odds ratios for the likelihood of being overweight and obese ${ }^{\S}$, by sociodemographic and smoking among random sample of 14176 Iranian women in the proportional odds model, 1999-2000.

\begin{tabular}{lcr}
\hline Variable & $\mathrm{OR}^{\#}$ & $95 \% \mathrm{CI}^{\dagger}$ \\
\hline Age group (years) & 1.00 & $1.96-2.35$ \\
$20-30$ & 2.16 & $2.67-3.23$ \\
$30-40$ & 2.93 & $2.63-3.32$ \\
$40-50$ & 2.96 & $1.76-2.25$ \\
$50-60$ & 1.99 & \\
$60-69$ & & $0.83-0.98$ \\
\hline Education level & 1.00 & $0.47-0.69$ \\
$\quad$ Basic & 0.90 & \\
Moderate & 0.57 & $1.26-1.50$ \\
High & & $1.27-1.51$ \\
\hline Economy index & 1.00 & $1.36-1.63$ \\
Low & 1.37 & \\
Lower-middle & 1.38 & $1.84-2.11$ \\
Upper-middle & 1.49 & \\
High & & \\
\hline Place of residence & 1.00 & $0.51-0.64$ \\
rural & 1.97 & \\
$\quad$ urban & & \\
\hline Workforce & 1.00 & $0.54-0.85$ \\
Inactive & 0.57 & \\
Active & & \\
\hline Smoking status & 1.00 & \\
Nonsmoker & 0.68 & \\
Smoker & & \\
\hline Marital status & 1.00 & \\
Non-married & 1.19 & \\
Married & & \\
\hline A & & \\
\hline
\end{tabular}

* Adjusted for all other variables.

$\S$ Obese, BMI $\geq 30$; overweight BMI 25.0-29.9.

₹BMI: body mass index (weight $(\mathrm{kg}) /$ height $\left.(\mathrm{m})^{2}\right)$.

\#OR: odds ratio.

${ }^{\dagger} \mathrm{CI}$ : confidence interval.

was noticeable. It is possible that the presence of a spouse may operate as a social factor on weight gain.

In Iran, it is commonly believed that overweight and obese people are lazy and gluttonous and they lack selfcontrol. Many obese people do not go out in public because the devices are too uncomfortable. For example, they cannot go to the movies because the seats are too small. Obese people are also more likely to lose the benefits of exercise and it may cause further weight gain. They often feel inferior to others because many people would not to be friends with an obese person. They often get disapproving stares from others. Some people believe that an obese person is taking up more space than he or she should and a job is often denied because of their weights.

Limitations and Strength. Some limitations of this study should be noted. Cause-and-effect cannot be inferred from our cross-sectional data. However, this should be confirmed by further longitudinal studies. It is a limitation that in this study marital status could be categorized into legally married and nonmarried only. Nonmarried people are also a very heterogeneous group and should be more closely examined in further studies. Unfortunately, income and physical activity were not used in our investigation.

Strengths of this study include the national random sample with a considerable age range and a BMI measurement that has been shown to be more valid than self-report measures on body weight and height. Obese people tend to underreport their BMI whereas thin people do the reverse $[56,57]$.

\section{Conclusions}

Increases in response were observed through the 20-60 years; however, all age beyond 60 years result in a decrease in probabilities of overweight and obesity. Women aged 20-40 
years gained weight faster than other groups. They may need additional information and more support on how to reduce their risk for weight gain through positive health behaviors.

\section{References}

[1] W. B. Kannel, R. B. D’Agostino, and J. L. Cobb, "Effect of weight on cardiovascular disease," American Journal of Clinical Nutrition, vol. 63, no. 3, pp. 195-225, 1996.

[2] T. K. Murphy, E. E. Calle, C. Rodriguez, H. S. Kahn, and M. J. Thun, "Body mass index and colon cancer mortality in a large prospective study," American Journal of Epidemiology, vol. 152, no. 9, pp. 847-854, 2000.

[3] P. A. Van den Brandt, D. Spiegelman, S. S. Yaun et al., "Pooled analysis of prospective cohort studies on height, weight, and breast cancer risk," American Journal of Epidemiology, vol. 152, no. 6, pp. 514-527, 2000.

[4] H. E. Resnik, P. Valsania, J. B. Halter, and X. Lin, "Relation of weight gain and weight loss on subsequent diabetes risk in overweight adults," Journal of Epidemiology and Community Health, vol. 54, no. 8, pp. 596-602, 2000.

[5] M. M. Corrada, C. H. Kawas, F. Mozaffar, and A. PaganiniHill, "Association of body mass index and weight change with all-cause mortality in the elderly," American Journal of Epidemiology, vol. 163, no. 10, pp. 938-949, 2006.

[6] P. K. E. Magnusson, F. Rasmussen, D. A. Lawlor, P. Tynelius, and D. Gunnell, "Association of body mass index with suicide mortality: a prospective cohort study of more than one million men," American Journal of Epidemiology, vol. 163, no. 1, pp. 1$8,2006$.

[7] K. A. O. Tikkinen, A. Auvinen, H. Huhtala, and T. L. J. Tammela, "Nocturia and obesity: a population-based study in Finland," American Journal of Epidemiology, vol. 163, no. 11, pp. 1003-1011, 2006.

[8] V. Mishra, F. Arnold, G. Semenov, R. Hong, and A. Mukuria, "Epidemiology of obesity and hypertension and related risk factors in Uzbekistan," European Journal of Clinical Nutrition, vol. 60, no. 12, pp. 1355-1366, 2006.

[9] L. H. Mccarthy, M. E. Bigal, M. Katz, C. Derby, and R. B. Lipton, "Chronic pain and obesity in elderly people: results from the einstein aging study," Journal of the American Geriatrics Society, vol. 57, no. 1, pp. 115-119, 2009.

[10] H. J. Milionis, M. Florentin, and S. Giannopoulos, "Metabolic syndrome and alzheimer's disease: a link to a vascular hypothesis?" CNS Spectrums, vol. 13, no. 7, pp. 606-613, 2008.

[11] S. Rossner, "Obesity: the disease of the twenty-first century," International Journal of Obesity, vol. 26, supplement 4, pp. S2S4, 2002.

[12] A. H. Mokdad, M. K. Serdula, W. H. Dietz, B. A. Bowman, J. S. Marks, and J. P. Koplan, "The spread of the obesity epidemic in the United States, 1991-1998," Journal of the American Medical Association, vol. 282, no. 16, pp. 1519-1522, 1999.

[13] J. S. Seidell and A. M. Rissanen, "Time trends in the worldwide prevalence of obesity," in Handbook of Obesity, G. A. Bray, Bouchard, and W. P. T. James, Eds., pp. 79-91, Marcel Dekker, New York, NY, USA, 1998.

[14] World Health Organisation, "Obesity: preventing and managing the global epidemic," Report of a WHO Consultation on Obesity, World Health Organisation, Geneva, Switzerland, 1998.

[15] K. Kuulasmaa, H. Tunstall-Pedoe, A. Dobson et al., "Estimation of contribution of changes in classic risk factors to trends in coronary-event rates across the WHO MONICA project populations," The Lancet, vol. 355, no. 9205, pp. 675-687, 2000.

[16] C. L. Ogden, M. D. Carroll, L. R. Curtin, M. A. McDowell, C. J. Tabak, and K. M. Flegal, "Prevalence of overweight and obesity in the United States, 1999-2004," Journal of the American Medical Association, vol. 295, no. 13, pp. 1549-1555, 2006.

[17] C. L. Birmingham, J. L. Muller, A. Palepu, J. J. Spinelli, and A. H. Anis, "The cost of obesity in Canada," Canadian Medical Association Journal, vol. 160, no. 4, pp. 483-488, 1999.

[18] J. C. Seidell, "Obesity in Europe: scaling an epidemic," International Journal of Obesity and Related Metabolic Disorders, vol. 19, pp. 1-4, 1995.

[19] J. C. Seidell, "Obesity, insulin resistance and diabetes-a worldwide epidemic," British Journal of Nutrition, vol. 83, supplement 1, pp. S5-S8, 2000.

[20] http://www.who.int/gho/ncd/risk_factors/overweight/en/index.html.

[21] http://www.who.int/mediacentre/factsheets/fs311/en/index .html.

[22] M. de Onis, M. Blössner, and E. Borghi, "Global prevalence and trends of overweight and obesity among preschool children," The American Journal of Clinical Nutrition, vol. 92, no. 5, pp. 1257-1264, 2010.

[23] K. M. Flegal, M. D. Carroll, R. J. Kuczmarski, and C. L. Johnson, "Overweight and obesity in the United States: prevalence and trends, 1960-1994," International Journal of Obesity, vol. 22, no. 1, pp. 39-47, 1998.

[24] C. E. Lewis, D. R. Jacobs, H. McCreath et al., "Weight gain continues in the 1990s: 10 year trends in weight and overweight from the CARDIA study," American Journal of Epidemiology, vol. 151, no. 12, pp. 1172-1181, 2000.

[25] A. Bagust, B. L. Roberts, A. R. Haycox, and S. Barrow, "The additional cost of obesity to the health service and the potential for resource savings from effective interventions," European Journal of Public Health, vol. 9, no. 4, pp. 258-264, 1999.

[26] J. Klumbiene, J. Petkeviciene, V. Helasoja, R. Prattala, and A. Kasmel, "Sociodemographic and health behaviour factors associated with obesity in adult populations in Estonia, Finland and Lithuania," European Journal of Public Health, vol. 14, no. 4, pp. 390-394, 2004.

[27] J. Sobal and A. J. Stunkard, "Socioeconomic status and obesity: a review of the literature," Psychological Bulletin, vol. 105, no. 2, pp. 260-275, 1989.

[28] The INCLEN Multicentre Collaborative Group, "Socioeconomic status and risk factors for cardiovascular disease: a multicentre collaborative study in the international clinical epidemiology network (INCLEN)," Journal of Clinical Epidemiology, vol. 47, no. 12, pp. 1401-1409, 1994.

[29] M. Nubé, W. K. Asenso-Okyere, and G. J. M. van den Boom, "Body mass index as indicator of standard of living in developing countries," European Journal of Clinical Nutrition, vol. 52, no. 2, pp. 136-144, 1998.

[30] T. Wilsgaard, B. K. Jacobsen, and E. Arnesen, "Determining lifestyle correlates of body mass index using multilevel analyses: the Tromso study, 1979-2001," American Journal of Epidemiology, vol. 162, no. 12, pp. 1179-1188, 2005.

[31] E. Bakhshi, M. R. Eshraghian, K. Mohammad et al., "The positive association between number of children and obesity in Iranian women and men: results from the national health survey," BMC Public Health, vol. 8, article 213, 2008.

[32] S. A. French, M. Story, and R. W. Jeffery, "Environmental influences on eating and physical activity," Annual Review of Public Health, vol. 22, pp. 309-335, 2001. 
[33] R. Hardy, D. A. Lawlor, S. Black, M. E. J. Wadsworth, and D. Kuh, "Number of children and coronary heart disease risk factors in men and women from a British birth cohort," BJOG: An International Journal of Obstetrics and Gynaecology, vol. 114, no. 6, pp. 721-730, 2007.

[34] M. L. Klem, J. E. Viteri, and R. R. Wing, "Primary prevention of weight gain for women aged 25-34: the acceptability of treatment formats," International Journal of Obesity, vol. 24, no. 2, pp. 219-225, 2000.

[35] S. Sarlio-Lahteenkorva and E. Lahelma, "The association of body mass index with social and economic disadvantage in women and men," International Journal of Epidemiology, vol. 28, no. 3, pp. 445-449, 1999.

[36] D. Laurier, M. Guiguet, N. P. Chau, J. A. Wells, and A. J. Valleron, "Prevalence of obesity: a comparative survey in France, the United Kingdom and the United States," International Journal of Obesity, vol. 16, no. 8, pp. 565-572, 1992.

[37] A. Molarius, J. C. Seidell, S. Sans, J. Tuomilehto, and K. E. Kuulasmaa, "Educational level, relative body weight, and changes in their association over 10 years: an international perspective from the WHO MONICA project," American Journal of Public Health, vol. 90, no. 8, pp. 1260-1268, 2000.

[38] S. P. Wamala, A. Wolk, and K. Orth-Gomer, "Determinants of obesity in relation to socioeconomic status among middleaged Swedish women," Preventive Medicine, vol. 26, no. 5, pp. 734-744, 1997.

[39] S. J. Paxton, A. Sculthorpe, and K. Gibbons, "Weight-loss strategies and beliefs in high and low socioeconomic areas of Melbourne," Australian Journal of Public Health, vol. 18, no. 4, pp. 412-417, 1994.

[40] M. G. Stephenson, A. S. Levy, N. L. Sass, and W. E. McGarvey, "1985 NHIS findings: nutrition knowledge and baseline data for the weight-loss objectives," Public Health Reports, vol. 102, no. 1, pp. 61-67, 1987.

[41] S. A. French and R. W. Jeffery, "Consequences of dieting to lose weight:effects on physical activity and mental health," Health Psychology, vol. 13, pp. 195-212, 1994.

[42] M. K. Serdula, M. E. Collins, D. F. Williamson, R. F. Anda, E. Pamuk, and T. E. Byers, "Weight control practices of U.S. adolescents and adults," Annals of Internal Medicine, vol. 119, no. 7, pp. 667-671, 1993.

[43] L. Biener and A. Heaton, "Women dieters of normal weight: their motives, goals, and risks," American Journal of Public Health, vol. 85, no. 5, pp. 714-717, 1995.

[44] S. A. French and R. W. Jeffery, "Current dieting, weight loss history, and weight suppression: behavioral correlates of three dimensions of dieting," Addictive Behaviors, vol. 22, no. 1, pp. 31-44, 1997.

[45] R. W. Jeffery, S. A. French, J. L. Forster, and V. M. Spry, "Socioeconomic status differences in health behaviors related to obesity: the healthy worker project," International Journal of Obesity, vol. 15, no. 10, pp. 689-696, 1991.

[46] P. Griffiths and M. Bentley, "Women of higher socio-economic status are more likely to be overweight in Karnataka, India," European Journal of Clinical Nutrition, vol. 59, no. 10, pp. 1217-1220, 2005.

[47] A. Ohlin and S. Rossner, "Development of body weight during and after pregnancy," in Proceedings of the Obesity in Europe 88: The First European Congress on Obesity, P. Bjortorp and S. Rossner, Eds., pp. 115-120, John Libbey, London, UK, 1989.

[48] A. Ohlin and S. Rossner, "Trends in eating patterns, physical activity and sociodemodemographic factors in relation to postpartum body weight development," British Journal of Nutrition, vol. 71, pp. 457-570, 1990.

[49] R. W. Jeffery, J. L. Forster, A. R. Folsom, R. V. Luepker, D. R. Jacobs Jr., and H. Blackburn, "The relationship between social status and body mass index in the Minnesota heart health program," International Journal of Obesity, vol. 13, no. 1, pp. 59-67, 1989.

[50] T. Kawada, "Difference of body mass index stratified by the period of smoking cessation from a cross-sectional study," Archives of Medical Research, vol. 35, no. 2, pp. 181-184, 2004.

[51] M. Laaksonen, O. Rahkonen, and R. Prattala, "Smoking status and relative weight by educational level in Finland, 19781995," Preventive Medicine, vol. 27, no. 3, pp. 431-437, 1998.

[52] E. Rasky, W. J. Stronegger, and W. Freidl, "The relationship between body weight and patterns of smoking in women and men," International Journal of Epidemiology, vol. 25, no. 6, pp. 1208-1212, 1996.

[53] A. Molarius, J. C. Seidell, S. Sans, J. Tuomilehto, and K. Kuulasmaa, "Smoking and relative body weight: an international perspective from the WHO MONICA project," Journal of Epidemiology and Community Health, vol. 51, no. 3, pp. 252260, 1997.

[54] R. W. Jeffery and A. M. Rick, "Cross-sectional and longitudinal associations between body mass index and marriage-related factors," Obesity Research, vol. 10, no. 8, pp. 809-815, 2002.

[55] J. Sobal, B. Rauschenbach, and E. A. Frongillo, "Marital status changes and body weight changes: a US longitudinal analysis," Social Science and Medicine, vol. 56, no. 7, pp. 1543-1555, 2003.

[56] G. Bostrom and F. Diderichsen, "Socioeconomic differences in misclassification of height, weight and body mass index based on questionnaire data," International Journal of Epidemiology, vol. 26, pp. 860-866, 1997.

[57] A. Kuskowska-Wolk, R. Bergstrom, and G. Bostrom, "Relationship between questionnaire data and medical records of height, weight and body mass index," International Journal of Obesity, vol. 16, no. 1, pp. 1-9, 1992. 


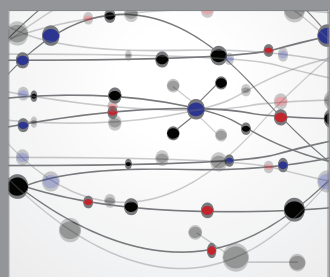

The Scientific World Journal
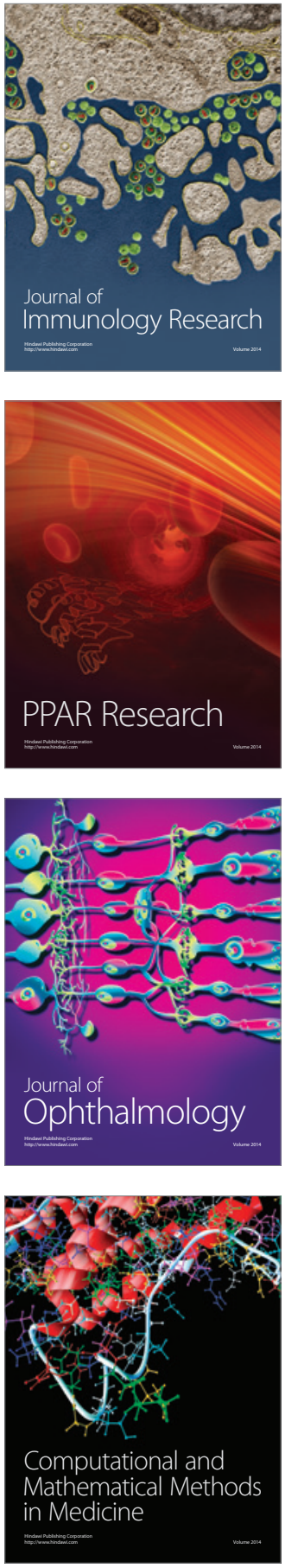

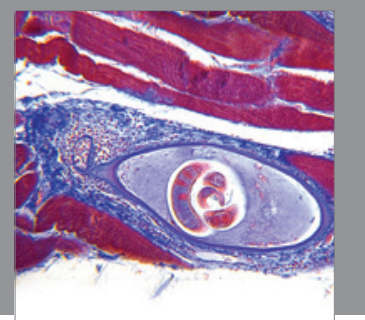

Gastroenterology

Research and Practice
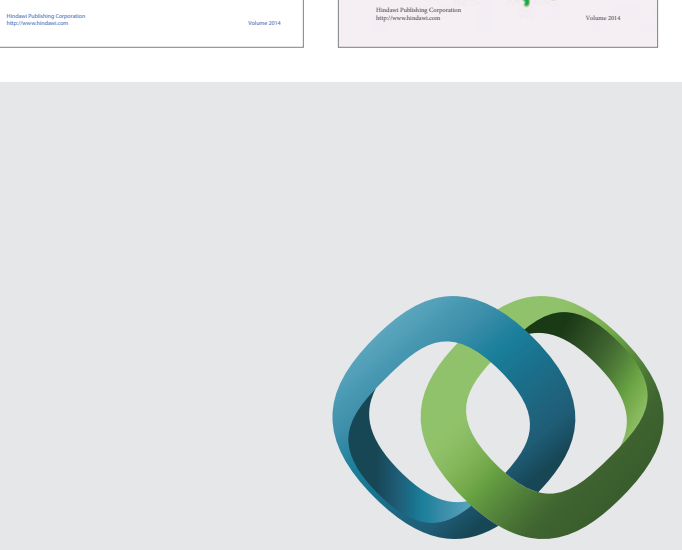

\section{Hindawi}

Submit your manuscripts at

http://www.hindawi.com
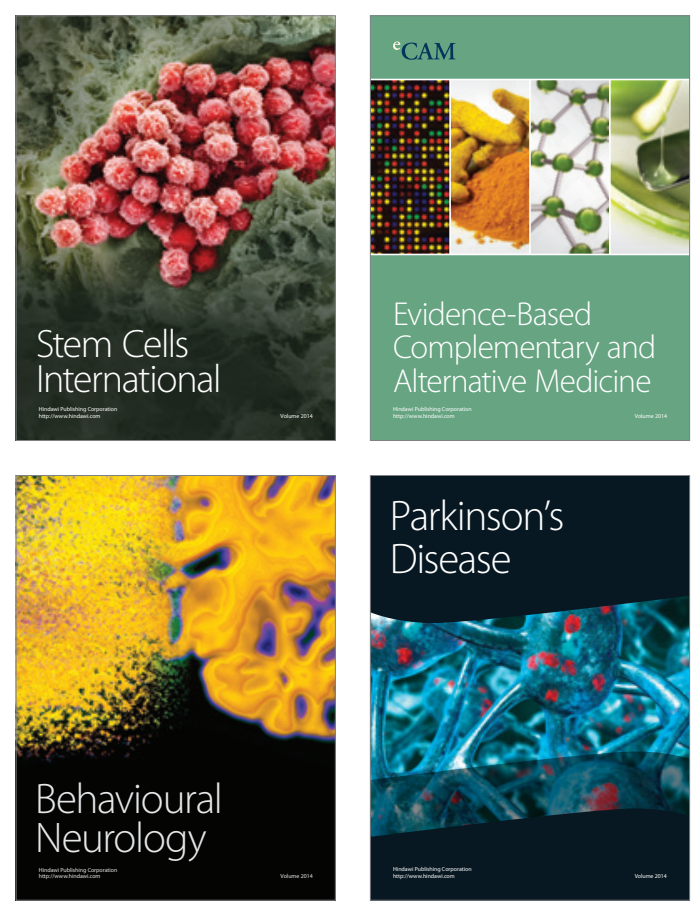

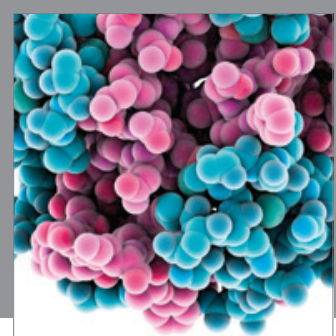

Journal of
Diabetes Research

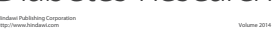

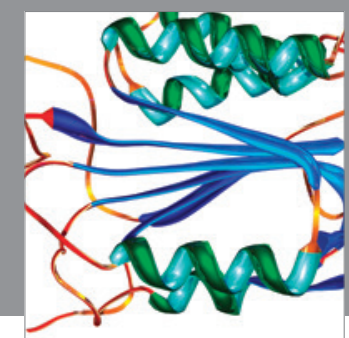

Disease Markers
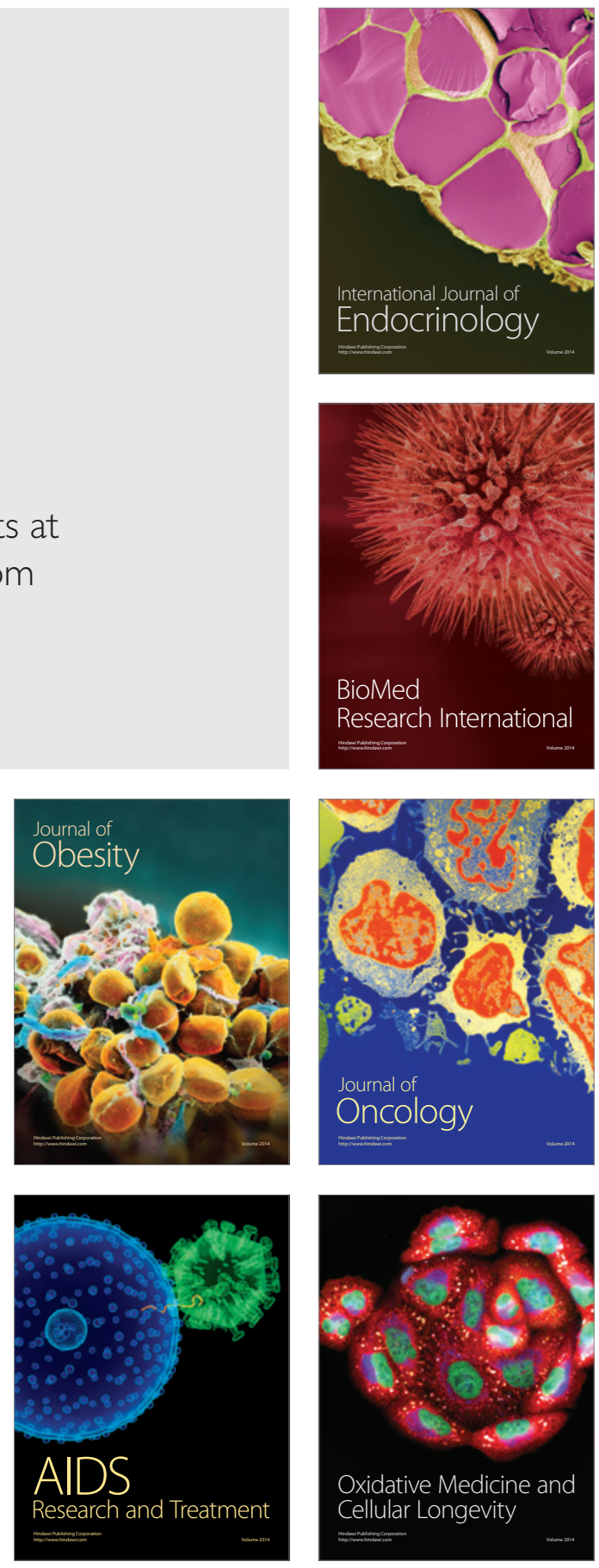